\title{
Efeito da composição genética e de fatores de meio sobre a produção de leite, a duração da lactação e a produção de leite por dia de intervalo de partos de vacas mestiças Holandês-Gir
}

\author{
[Effects of genetic composition and environmental factors on milk production, lactation length and milk production \\ per day of calving interval in crossbred Holstein-Gyr cows] \\ J.R. Glória ${ }^{1}$, J.A.G. Bergmann ${ }^{2}$, R.B. Reis ${ }^{2}$, M.S. Coelho ${ }^{3}$, M.A. Silva ${ }^{2}$ \\ ${ }^{1}$ Aluna de pós-graduação - EV-UFMG \\ ${ }^{2}$ Escola de Veterinária - UFMG \\ Caixa Postal 567 \\ 30123-970 - Belo Horizonte, MG \\ ${ }^{3}$ Médico veterinário autônomo
}

\begin{abstract}
RESUMO
Utilizou-se o método dos quadrados mínimos para avaliar os efeitos da composição genética (CG) e dos fatores de meio sobre a produção total de leite (PL), duração da lactação (DL) e produção de leite por dia de intervalo de partos (P/I) $(\mathrm{n}=2.016)$ de 822 vacas mestiças $(1 / 2,3 / 4$ e $7 / 8)$ Holandês-Gir, criadas no oeste de Minas Gerais. O efeito da capacidade prevista de transmissão (PTA) dos touros da raça Holandesa sobre a PL de suas filhas cruzadas também foi avaliado. O efeito da CG sobre as três características foi importante fonte de variação, sendo que a PL, a DL e a P/I aumentaram com o incremento da contribuição da raça Holandesa. As médias para PL foram $3549,3 \pm 39,3 \mathrm{~kg}, 4331,7 \pm 56,2 \mathrm{~kg}$ e $4515,7 \pm 115,9 \mathrm{~kg}$; para DL, 306,5 $\pm 1,9$ dias, $328,2 \pm 2,5$ dias e $337,0 \pm 4,6$ dias; e para P/I, $9,0 \pm 0,1 \mathrm{~kg}$, $10,6 \pm 0,2 \mathrm{~kg}$ e $11,0 \pm 0,3 \mathrm{~kg}$ por dia, respectivamente, para vacas $1 / 2,3 / 4$ e 7/8 Holandês-Gir. Estação de parição foi importante fonte de variação da PL das vacas 3/4 e da DL de vacas 3/4 e 1/2 Holandês-Gir. Maiores PL e DL foram observadas nas lactações iniciadas no final do período chuvoso. O efeito da idade da vaca ao parto sobre a PL foi linear ascendente para vacas $1 / 2$ e 3/4 Holandês-Gir e curvilíneo para vacas $7 / 8$ Holandês-Gir, com produção máxima $(4733,5 \mathrm{~kg}$ ) na segunda lactação. Para DL esse efeito foi curvilíneo para vacas 1/2 e 3/4 Holandês-Gir, com mínimos de 284,7 e 309,2 dias aos 7,3 e 5,7 anos de idade, respectivamente; e linear descendente para vacas $7 / 8$ Holandês-Gir. Já o efeito da idade da vaca sobre P/I foi linear ascendente para o conjunto $3 / 4$ e $7 / 8$, e curvilíneo para as $1 / 2$ Holandês-Gir, com o máximo de $9,5 \mathrm{~kg} /$ dia de intervalo de partos aos 6,4 anos de idade. O efeito do PTA de touros sobre a PL de suas filhas não foi diferente de zero. As estimativas de repetibilidade para PL foram 0,72, 0,69 e 0,63, respectivamente, para vacas $1 / 2,3 / 4$ e 7/8 Holandês-Gir.
\end{abstract}

Palavras-chave: vaca de leite, grupo genético, produção de leite, duração da lactação, fatores de meio

\begin{abstract}
The effects of genetic composition $(G C)$ and environmental factors on milk production (MP), lactation length (LL) and milk yield per day of calving intervals (P/I) $(n=2,016)$ of 822 crossbred (1/2, 3/4 and 7/8) Holstein-Gyr cows, raised in the West of Minas Gerais State, Brazil, were evaluated using least squares methodology. The effect of predicted transmitting ability (PTA) of the Holstein sires on MP of their daughters was also evaluated. The effect of genetic composition on the three traits was an important source of variation. MP, LL and P/I increased with the increase of Holstein contribution. Season of calving was an important source of variation for MP of $3 / 4$ cows and for $L L$ of $3 / 4$ and $1 / 2$ cows. The
\end{abstract}

Recebido em 29 de junho de 2006

Aceito em 20 de novembro de 2006

* Autor para correspondência (corresponding author)

E-mail: bergmann@vet.ufmg.br 
highest MP and LL were observed for lactations starting at the end of the rainy season. The effect of age at calving on MP was linear for $1 / / 2$ and 3/4 cows and curvilinear for 7/8 cows. For LL the effect of age at calving was curvilinear for $1 / 2$ and $3 / 4$ cows and linear for $7 / 8$ cows. On P/I was linear for $3 / 4$ and $7 / 8$ cows and curvilinear for 1/2 cows. The effect of PTA on MP was not different from zero. Estimated repeatability for MP were .72, .69 and .63, respectively, for the 1/2,3/4 and 7/8 Holstein-Gyr cows.

Keywords: dairy cow, crossbred, milk yield, lactation length, environmental factors

\section{INTRODUÇÃO}

Apesar de serem muitos os estudos que avaliam o efeito da composição genética Holandês-Zebu sobre a produção de leite e a duração da lactação, os resultados são contraditórios. Junqueira Filho (1989), em vacas mestiças Holandês-Zebu com composição genética variada, verificou média de produção de leite de $2.989 \mathrm{~kg} /$ lactação. Gonçalves et al. (1997), em rebanhos mestiços Holandês-Gir, verificaram médias de produção de leite por dia de intervalo de partos de $11,9 \mathrm{~kg} / \mathrm{dia}$ e Barbosa et al. (2001), em um rebanho mestiço Europeu-Zebu mantido em regime de pastagem com suplementação alimentar durante a seca e concentrado durante todo o ano, encontraram média de produção de $5,7 \mathrm{~kg} /$ dia. Vasconcelos et al. (1989) e Durães et al. (2001) mostraram que a composição genética influenciou a produção de leite e de gordura. No primeiro estudo, as maiores produções de leite e os maiores períodos de lactação foram observados nos animais $1 / 2$ e $3 / 4$ Holandês-Zebu e as menores nos animais $7 / 8$ a 31/32 de genética da raça Holandesa.

Freitas et al. (2001) e Valente et al. (2002) verificaram que a menor produção de leite ocorreu em vacas 1/2 Holandês-Gir e que a produção aumentou com o aumento da contribuição composição genética da raça Holandesa. Gonçalves et al. (1997) observaram influência do grupo genético sobre a produção de leite por dia de intervalo de partos, em que menores médias foram observadas para animais 1/2 Holandês-Gir e puros por cruza, e os demais grupos não diferiram entre si.

Além da composição genética, diversos fatores de ambiente influenciam a produção de leite e a duração da lactação das vacas mestiças. $\mathrm{O}$ efeito do ano de parição está associado às alterações na disponibilidade e qualidade dos alimentos, às diferenças no manejo, às mudanças genéticas do rebanho e, também, às oscilações econômicas.
Em estudo da produção de vacas mestiças $1 / 2$ Europeu-Zebu a puro por cruza Europeu, Reis at al. (1983ab) encontraram efeito significativo do ano de parto sobre a produção total de leite e sobre o período de lactação, com tendência de aumento na produção de leite e queda na duração da lactação ano após ano. $\mathrm{O}$ efeito do mês ou da estação de parto sobre a produção de leite e a duração da lactação reflete diferenças de alimentação entre as épocas das águas e da seca. Junqueira Filho (1989) e Deresz et al. (2003), ao avaliarem dados de vacas mestiças EuropeuZebu, criadas com suplementação de concentrado nas duas estações ou só na estação chuvosa, respectivamente, observaram maiores produções obtidas nas lactações iniciadas na época seca. Reis et al. (1983a) e Vasconcelos et al. (1989) observaram maiores períodos de lactação nas lactações iniciadas na estação seca, possivelmente em função das condições climáticas e ao melhor aporte alimentar.

Também a idade da vaca tem sido relacionada com a produção de leite e a duração da lactação. Em condições normais, vacas produzem menos na primeira lactação em decorrência da incompleta maturidade fisiológica. Nos trabalhos de Reis et al. (1983ab), a produção de leite e o período de lactação aumentaram até a sexta e quinta ordem de lactação, respectivamente, com queda a partir desses pontos.

Baseados nas propriedades de hormônios do crescimento e prolactina, atribuídas aos hormônios lactógenos, Basu e Tomar (1981) afirmaram que a produção de leite na lactação também pode ser influenciada pelo peso do bezerro parido. Entretanto, os trabalhos na literatura não têm mostrado produções estatisticamente diferentes para vacas que parem crias de sexo diferente.

Um questionamento freqüente dos produtores e mesmo dos pesquisadores (Pereira, 1998) está relacionado às possíveis vantagens, ou não, em 
se utilizar sêmen de reprodutores da raça Holandesa, avaliados em populações de raça pura e nas condições de manejo intensivo dos países de clima temperado. Na raça Holandesa, Houri Neto et al. (1996), ao compararem produções de leite de filhas dos mesmos touros, obtidas nos Estados Unidos da América e no Brasil, encontraram correlação genética de 0,60. Concluíram que as progênies não tiveram o mesmo comportamento nos diferentes ambientes. Entretanto, o efeito do uso de touros provados, com diferentes níveis de capacidade prevista de transmissão (PTA) sobre a produção de leite de suas filhas mestiças não foi ainda estudado.

O conhecimento do valor da repetibilidade da produção de leite possibilita inferir até que ponto o desempenho de um animal para determinada característica, repete-se durante sua vida produtiva. Polastre (1985), ao estudar lactações de vacas mestiças Holandês-Zebu, estimou valor de repetibilidade de 0,36 para produção de leite observada e Freitas et al. (1991), de 0,28.
Os objetivos deste estudo foram avaliar a influência da composição genética, do ano e da estação de parição, da idade ao parto e do sexo da cria sobre a produção total de leite, a duração da lactação e a produção de leite por dia de intervalo de partos de vacas mestiças HolandêsGir e estudar o efeito do PTA de touros da raça Holandesa sobre a produção de leite de suas filhas mestiças.

\section{MATERIAL E MÉTODOS}

Foram utilizadas informações de 2.016 lactações cujos partos ocorreram entre 1998 e 2003 de 822 vacas 1/2 (407), 3/4 (328) e 7/8 (87) HolandêsGir, criadas na Fazenda Santa Luzia, Passos-MG, nascidas entre 1992 e 2001 (Tab. 1). Durante o período das águas (de novembro a abril), as vacas alimentaram-se exclusivamente de pasto e concentrado e no período da seca (de maio a outubro) elas receberam silagem de milho e cana de açúcar como suplementação volumosa.

Tabela 1. Distribuição do número de observações (\%) por grupo genético e ano de parição em vacas leiteiras Holandês-Gir

\begin{tabular}{lccccccc}
\hline \multirow{2}{*}{ Composição genética } & \multicolumn{7}{c}{ Ano de parição } \\
\cline { 2 - 8 } & 1998 & 1999 & 2000 & 2001 & 2002 & 2003 & Total \\
\hline 1/2 Holandês-Gir & 67 & 112 & 156 & 247 & 277 & 306 & 1165 \\
& $(65,1)$ & $(64,4)$ & $(59,3)$ & $(61,9)$ & $(53,3)$ & $(54,9)$ & \\
3/4 Holandês-Gir & 28 & 51 & 87 & 123 & 186 & 200 & 675 \\
& $(27,2)$ & $(29,3)$ & $(33,1)$ & $(30,8)$ & $(35,8)$ & $(35,9)$ & \\
$7 / 8$ Holandês-Gir & 8 & 11 & 20 & 29 & 57 & 51 & 176 \\
& $(7,7)$ & $(6,3)$ & $(7,6)$ & $(7,3)$ & $(10,9)$ & $(9,2)$ & \\
\hline Total & 103 & 174 & 263 & 399 & 520 & 557 & 2016 \\
& $(100)$ & $(100)$ & $(100)$ & $(100)$ & $(100)$ & $(100)$ & \\
\hline
\end{tabular}

Os dados foram analisados pelo método dos quadrados mínimos, utilizando-se o procedimento GLM do pacote estatístico SAS (User's..., 1996). Inicialmente, foram testados modelos para produção total de leite na lactação, duração da lactação e produção por dia de intervalo de partos, considerando informações dos animais do conjunto de todas as composições genéticas com o objetivo de verificar a presença de interações entre essa variável e os fatores de ambiente. Para a produção total de leite, duração da lactação e produção por dia de intervalo de partos o modelo estatístico utilizado foi:

$Y_{i j k l m n}=\alpha+G_{i}+A_{j}+E_{l}+X_{m}+b_{1}\left(I_{i j k l m n}-\bar{I}\right)+$ $b_{2}\left(I_{i j k l m n}-\bar{I}\right)^{2}+G A_{i j}+G E_{i l}+G_{i} b_{1}\left(I_{i j k l m n}-\bar{I}\right)+$ $G_{i} b_{2}\left(I_{i j k l m n}-\bar{I}\right)^{2}+e_{i j k l m n}$, em que:
$Y=$ produção total de leite, duração da lactação ou produção de leite por dia de intervalo de partos;

$\alpha=$ constante;

$G_{i}=$ efeito fixo da composição genética $i, i=1$ para $1 / 2$ Holandês-Gir, $i=2$ para $3 / 4$ Holandês-Gir e $i=3$ para 7/8 HolandêsGir;

$A_{j}=$ efeito fixo do ano de parição $j, j=$ $1998, \ldots ., 2003$;

$E_{l}=$ efeito fixo da época de parição $l, l=1$ para início de seca (de maio a julho), $l=2$ final de seca (de agosto a outubro), $l=3$ para início de chuvas (de novembro a janeiro) e $l=4$ para final de chuvas (de fevereiro a abril); 
$X_{m}=$ efeito fixo do sexo da cria $m, m=1$ para macho e $m=2$ para fêmea;

$b_{1}$ e $b_{2}=$ coeficientes de regressão linear e quadrático da produção de leite ou da duração da lactação $Y_{i j k l m}$, sobre a idade do animal ao parto;

$I_{i j k l m n}=$ idade do animal ao parto;

$\bar{I}=$ média da idade do animal ao parto;

$G A_{i j}=$ interação entre a composição genética e o ano de parição;

$G E_{i l}=$ interação entre a composição genética e a época de parição;

$G_{i} b_{1}\left(I_{i j k l m n}-\bar{I}\right)=$ interação entre a composição genética e o efeito linear da idade do animal ao parto;

$G_{i} b_{2}\left(I_{i j k l m n}-\bar{I}^{2}=\right.$ interação entre a composição genética e o efeito quadrático da idade do animal ao parto;

$e_{i j k l m n}=$ resíduo,

Observada a presença de interações significativas entre composição genética e variáveis associadas aos efeitos não-genéticos, optou-se por testar modelos semelhantes para cada composição genética separadamente. Avaliou-se, também, o efeito da covariável capacidade prevista de transmissão (PTA) dos touros da raça Holandesa sobre a produção total de leite de suas filhas cruzadas. As PTA utilizadas foram obtidas da avaliação genética da Holstein Association de maio de 2004 , sendo que a mínima foi de -1205 e a máxima de $915 \mathrm{~kg}$ de leite (Tab. 2) (Dairy ..., 2004; USDA, 2004).

As estimativas de repetibilidadade para produção de leite foram obtidas, utilizando o método da máxima verossimilhança, por meio do procedimento VARCOMP do pacote estatístico SAS (User's..., 1996), a partir dos resíduos gerados pelos modelos selecionados.

\section{RESULTADOS E DISCUSSÃO}

A Tab. 3 inclui as médias ajustadas e erros padrão para produção de leite, duração da lactação e produção de leite por dia de intervalo de partos, de acordo com a composição genética.

Tabela 2. Distribuição dos valores máximos, médios e mínimos da capacidade prevista de transmissão (PTA) de acordo com a composição genética

\begin{tabular}{lcccccc}
\hline \multicolumn{1}{c}{ Composição genética } & $\mathrm{N}^{\circ}$ touros & $\begin{array}{c}\text { PTA } \\
\text { média }\end{array}$ & $\begin{array}{c}\text { PTA } \\
\text { mínima }\end{array}$ & $\begin{array}{c}\text { PTA } \\
\text { máxima }\end{array}$ & $\begin{array}{c}\mathrm{N}^{\circ} \\
\text { animais }\end{array}$ & $\begin{array}{c}\mathrm{N}^{\circ} \\
\text { lactações }\end{array}$ \\
\hline 1/2 Holandês-Gir & 13 & 339 & -622 & 915 & 101 & 186 \\
3/4 Holandês-Gir & 30 & 309 & -1205 & 838 & 163 & 231 \\
7/8 Holandês-Gir & 26 & 299 & -1205 & 838 & 69 & 117 \\
\hline Total & 46 & 268 & -1205 & 915 & 333 & 534 \\
\hline
\end{tabular}

Tabela 3. Médias ajustadas e erros-padrão para produção de leite, duração da lactação e produção de leite por dia de intervalo de partos, de acordo com cada composição genética

\begin{tabular}{lccc}
\hline \multicolumn{1}{c}{ Composição genética } & $\begin{array}{c}\text { Produção de leite, } \\
\mathrm{kg}\end{array}$ & $\begin{array}{c}\text { Duração da } \\
\text { lactação, dias }\end{array}$ & $\begin{array}{c}\text { Produção de leite por dia de } \\
\text { intervalo de partos, kg/dia }\end{array}$ \\
\hline 1/2 Holandês-Gir & $3549,3 \pm 39,3$ & $306,5 \pm 1,9$ & $9,0 \pm 0,1$ \\
3/4 Holandês-Gir & $4331,7 \pm 56,2$ & $328,2 \pm 2,5$ & $10,6 \pm 0,2$ \\
7/8 Holandês-Gir & $4515,7 \pm 115,9$ & $337,0 \pm 4,6$ & $11,0 \pm 0,3$ \\
\hline
\end{tabular}

Para produção total de leite na lactação o efeito de composição genética foi importante (Tab. 4), sendo que a comparação por contraste envolvendo as médias ajustadas evidenciou diferença $(\mathrm{P}<0,01)$ entre as produções de leite de vacas de composição genética $1 / 2$ e $3 / 4$ Holandês-Gir, e entre as médias ajustadas das vacas de composição genética $3 / 4$ e $7 / 8$ Holandês-Gir $(\mathrm{P}<0,01)$, refletindo o aumento da produção total de leite com o aumento contribuição genética da raça Holandesa.
Provavelmente, as condições de ambiente, incluindo as práticas de manejo, não foram limitantes para que as vacas com maior proporção de genética da raça Holandesa expressassem seu maior potencial para produção de leite. Resultados semelhantes foram obtidos por Freitas et al. (2001) e Valente et al. (2002). No entanto, Reis et al. (1983b) e Vasconcelos et al. (1989) observaram maiores produções para animais com menor proporção genética da raça Holandesa. 
Tabela 4. Análise de variância do modelo final para produção de leite considerando todas as composições genéticas

\begin{tabular}{lccc}
\multicolumn{1}{c}{ Fonte de variação } & $\begin{array}{c}\text { Grau de } \\
\text { liberdade }\end{array}$ & Quadrado médio & $\begin{array}{c}\text { Nível de } \\
\text { significância }\end{array}$ \\
\hline Ano de parto & 5 & 12718367 & 0,0001 \\
Estação de parto & 3 & 6768355 & 0,0005 \\
Composição genética & 2 & 54139069 & 0,0001 \\
Idade ao parto & 1 & 8786053 & 0,0054 \\
Ano de parto x composição genética & 10 & 3914029 & 0,0002 \\
Idade ao parto ${ }^{2}$ x composição genética & 3 & 3656777 & 0,0218 \\
Erro & 1947 & 1134544 & \\
\hline Total corrigido & 1971 & & \\
\hline
\end{tabular}

A interação entre o ano de parto e a composição genética individualmente também foi importante fonte de variação sobre a produção total de leite $(\mathrm{P}<0,01)$ (Tab. 4). Diferentes condições climáticas e de manejo a cada ano podem favorecer ou desfavorecer uma ou outra composição genética.

Ao testar modelos para cada composição genética individualmente, verificou-se que a estação de parição foi fator importante somente sobre a variação da produção total de leite das vacas $3 / 4$ Holandês-Gir $(\mathrm{P}<0,05)$. Maiores produções foram observadas para lactações iniciadas no final do período chuvoso (Tab. 5). Este resultado pode estar relacionado ao fato de que os animais que pariram no final da estação chuvosa passaram a maior parte da lactação recebendo a dieta fornecida na seca e ainda tiveram os últimos meses da lactação coincidindo com o início da estação chuvosa quando a disponibilidade de pastagens de melhor qualidade permitiu maior persistência da lactação, ou mesmo ocasionado um segundo pico de produção, de menor intensidade. Os animais que pariram no final da estação seca passaram a maior parte da lactação recebendo somente pasto e concentrado e tiveram o terço final da lactação coincidindo com o início da seca. Provavelmente, por eles estarem em final de lactação, não usufruíram uma dieta melhor que possibilitasse a manutenção da lactação por um período maior Nos resultados observados por Vasconcelos et al. (1989) e Junqueira Filho (1989), maiores produções foram obtidas nas lactações iniciadas no período seco.

Tabela 5. Médias ajustadas e erros-padrão para produção de leite de vacas 3/4 Holandês-Gir, segundo a estação de parição

\begin{tabular}{lc}
\hline Estação de parição & Produção de leite, $\mathrm{kg}$ \\
\hline Final chuvas & $4547,0 \pm 9+5,1$ \\
Início seca & $4326,1 \pm 84,8$ \\
Final seca & $4170,0 \pm 99,2$ \\
Início chuvas & $4272,9 \pm 132,9$ \\
\hline
\end{tabular}

Esses modelos mostraram também que para vacas $1 / 2$ e 3/4 Holandês-Gir o efeito da idade da vaca ao parto sobre a produção total de leite foi linear $(\mathrm{P}<0,01)$, tendo sido observados aumentos de $52,6 \mathrm{~kg}$ e $105,5 \mathrm{~kg}$ de leite por ano de incremento na idade da vaca ao parto, respectivamente. Para animais 7/8 Holandês-Gir esse efeito foi curvilíneo, com produção máxima aos quatro anos e três meses de idade, o que correspondeu, aproximadamente, à segunda lactação (Fig. 1). Estes resultados podem ser explicados pelas mudanças físiológicas do animal com o avançar da idade, isto é, vacas jovens além de estarem produzindo também estão em crescimento, portanto com maiores exigências nutricionais. À medida que se tornam adultos seus sistemas digestivo, circulatório, respiratório, mamário atingem completo desenvolvimento, permitindo a expressão de todo o potencial genético para produção. Outra possível causa associada a esse efeito pode ter sido a seleção praticada para produção leiteira ao longo das sucessivas lactações. Nesse caso, apenas as vacas 1/2 e 3/4 Holandês-Gir de maior produção permaneceram no rebanho até idades mais avançadas. Já as vacas de composição genética 7/8 Holandês-Gir, por terem maiores produções, tenderam a permanecer no rebanho até idades mais avançadas, possibilitando a manifestação do efeito curvilíneo para esta variável.

O coeficiente de regressão da produção de leite de vacas mestiças em relação à PTA de seus pais não foi diferente de zero para nenhuma das composições genéticas. Este resultado sugere que as diferenças observadas entre as PTA de touros da raça Holandesa, obtidos em avaliações genéticas americanas, podem não refletir diretamente diferenças entre as produções de leite de suas filhas 
mestiças, a partir da base Zebu e criadas em condições tropicais.

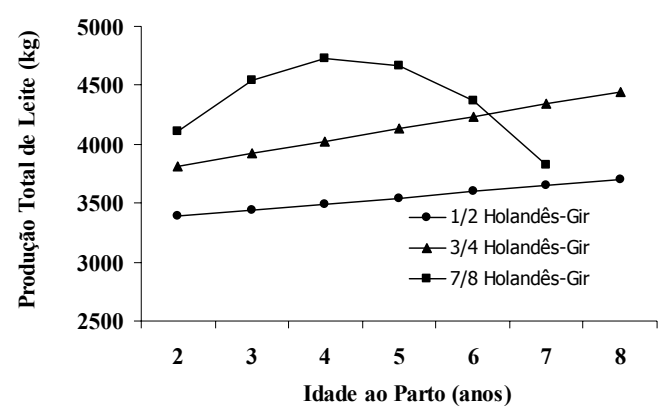

Figura 1. Regressão da produção total de leite $(\mathrm{kg})$, em relação à idade da vaca ao parto.

Para duração da lactação o efeito de composição genética foi importante (Tab. 6), e a comparação por contraste envolvendo as médias estimadas evidenciou diferença $(\mathrm{P}<0,01)$ entre a duração da lactação de vacas $1 / 2$ e 3/4 Holandês-Gir, e entre as de composição genética 3/4 e 7/8 HolandêsGir $(\mathrm{P}<0,01)$. A duração média da lactação foi menor em animais com maior percentual de genes Gir (Tab. 3). Esse resultado era esperado, pois, em geral, animais zebuínos têm períodos de lactação mais curtos. Médias menores foram encontradas por Lemos et al. (1994) e Freitas et al. (2001)

Ao analisar modelos para cada composição genética individualmente, verificou-se a estação de parição mostrou ser fonte de variação importante sobre a duração da lactação das vacas $1 / 2(\mathrm{P}<0,01)$ e $3 / 4$ Holandês-Gir $(\mathrm{P}<0,05)$. Em ambos os casos, maior duração foi observada para lactações iniciadas no período das chuvas (Tab. 7). Os resultados encontrados podem ser explicados pelo fato de os animais receberem alimentação volumosa no cocho durante o período de maior produção e ainda os animais que parem no final da estação chuvosa têm o terço final da lactação coincidente com o início do período chuvoso, época em que a grande disponibilidade de forragens verdes permite maior persistência da lactação. Matos (1983) encontrou maior duração para lactações iniciadas na segunda metade do período chuvoso e primeira metade do período seco.

Tabela 6. Análise de variância do modelo final para duração da lactação considerando todas as composições genéticas

\begin{tabular}{lccc} 
Fonte de variação & $\begin{array}{c}\text { Grau de } \\
\text { liberdade }\end{array}$ & Quadrado médio & $\begin{array}{c}\text { Nível de } \\
\text { significância }\end{array}$ \\
\hline Ano de parto & 5 & 13123 & 0,0017 \\
Estação de parto & 3 & 27325 & 0,0001 \\
Composição genética $^{\text {and }}$ & 2 & 37457 & 0,0001 \\
Idade ao parto $^{2}$ & 1 & 101248 & 0,0001 \\
Idade ao parto $^{2}$ & 1 & 42338 & 0,0004 \\
Idade ao parto $^{2}$ x composição genética & 2 & 16674 & 0,0074 \\
Erro & 2001 & 3389 & \\
\hline Total corrigido & 2015 & & \\
\hline
\end{tabular}

Tabela 7. Médias ajustadas e erros-padrão para duração da lactação de vacas 1/2 e 3/4 Holandês-Gir, segundo a estação de parição

\begin{tabular}{lcccc}
\hline Composição genética & Final chuvas & Início seca & Final seca & Início chuvas \\
\hline 1/2 Holandês-Gir & $317,5 \pm 4,0$ & $300,6 \pm 2,8$ & $298,3 \pm 3,5$ & $310,7 \pm 4,1$ \\
3/4 Holandês-Gir & $333,1 \pm 5,0$ & $322,1 \pm 4,5$ & $315,5 \pm 5,2$ & $332,4 \pm 7,0$ \\
\hline
\end{tabular}


$\mathrm{O}$ efeito da idade da vaca ao parto sobre a duração da lactação de vacas $1 / 2$ e $3 / 4$ HolandêsGir foi curvilíneo, com durações mínimas observadas aos sete anos e três meses e aos cinco anos e sete meses de idade ao parto, respectivamente. No entanto, para animais $7 / 8$ Holandês-Gir, esse efeito foi linear com redução de 12,1 dias na duração da lactação a cada ano a mais na idade da vaca ao parto (Fig. 2). Maior duração nas primeiras ordens de lactação está relacionada a maior período de serviço, geralmente observado em animais que ainda estão em crescimento, visto que eles têm que destinar nutrientes para o crescimento, produção de leite e ainda fornecer condições para a reprodução. A elevada média de duração da lactação nas primíparas $1 / 2$ Holandês-Gir também está associada ao bom manejo, principalmente com relação ao seu amansamento. Resultados semelhantes foram encontrados por Vasconcelos (1985), em que o maior período de lactação foi obtido para a segunda ordem de parto, seguido da primeira, com tendência de diminuição com o avançar da idade. No entanto, outros resultados registrados são divergentes, uma vez que o período de lactação aumentou até a quinta ordem de parto e voltou a cair, posteriormente (Reis, 1983a)

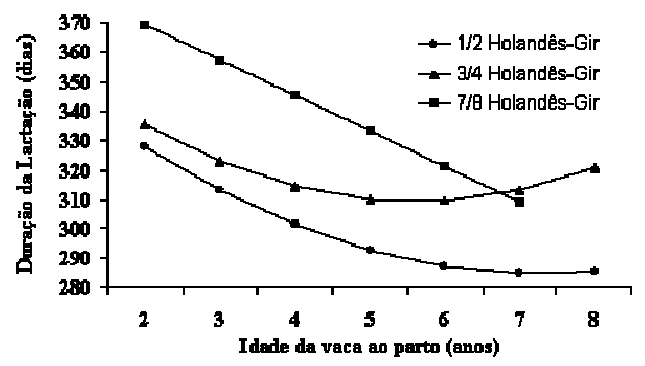

Figura 2. Regressão da duração da lactação (dias), em relação à idade da vaca ao parto.
Para produção de leite por dia de intervalo de partos o efeito da composição genética foi importante $(\mathrm{P}<0,01)$ (Tab. 8). As comparações por contrastes mostraram diferença entre médias estimadas da produção por dia de intervalo de partos de vacas $1 / 2$ e $3 / 4$ Holandês-Gir $(\mathrm{P}<0,01)$. No entanto, não foi observada diferença entre as médias estimadas para vacas $3 / 4$ e 7/8 Holandês$\operatorname{Gir}(\mathrm{P}=0,26)$ (Tab. 3).

Ao testar um modelo para produção de leite por dia de intervalo de partos de vacas $1 / 2$ HolandêsGir e um outro para vacas 3/4 e 7/8 Holandês-Gir em conjunto, foi verificado que o efeito da idade ao parto sobre a produção de leite por dia de intervalo de partos de vacas $1 / 2$ Holandês-Gir foi curvilíneo, com máxima produção prevista para 6 anos e 4 meses. No entanto, para o conjunto de vacas 3/4 e 7/8 Holandês-Gir, esse efeito foi linear, com aumento de $0,303 \mathrm{~kg} /$ dia de intervalo de partos para cada ano a mais na idade da vaca ao parto (Fig. 3). Provavelmente, este resultado foi conseqüência do aumento da produção de leite e da diminuição do intervalo de partos com $\mathrm{o}$ avançar da idade.

O sexo da cria parida foi importante fonte da variação sobre a produção de leite por dia de intervalo de partos $(\mathrm{P}=0,03)$ quando foram analisadas lactações de animais $1 / 2$ Holandês-Gir separadamente. A diferença encontrada foi de, aproximadamente, $0,356 \mathrm{~kg} / \mathrm{dia}$ de dia de intervalo de partos a mais quando a cria era fêmea. Considerando um intervalo de partos médio de 391 dias, a produção total de leite no intervalo de partos das vacas 1/2 Holandês-Gir seria de $139 \mathrm{~kg}$ maior para vacas parindo fêmeas.

Tabela 8. Análise de variância do modelo final para produção de leite por dia de intervalo de partos considerando todas as composições genéticas

\begin{tabular}{lccc}
\multicolumn{1}{c}{ Fonte de variação } & $\begin{array}{c}\text { Grau de } \\
\text { liberdade }\end{array}$ & Quadrado médio & $\begin{array}{c}\text { Nível de } \\
\text { significância }\end{array}$ \\
\hline Ano de parto & 4 & 44,98 & 0,0001 \\
Composição genética $^{\text {Idade ao parto }}$ & 2 & 289,03 & 0,0001 \\
Idade ao parto $^{2}$ & 1 & 72,14 & 0,0003 \\
Idade ao parto x composição genética $_{\text {Erro }}$ & 1 & 36,50 & 0,0101 \\
Total corrigido & 8 & 14,37 & 0,0078 \\
\hline
\end{tabular}




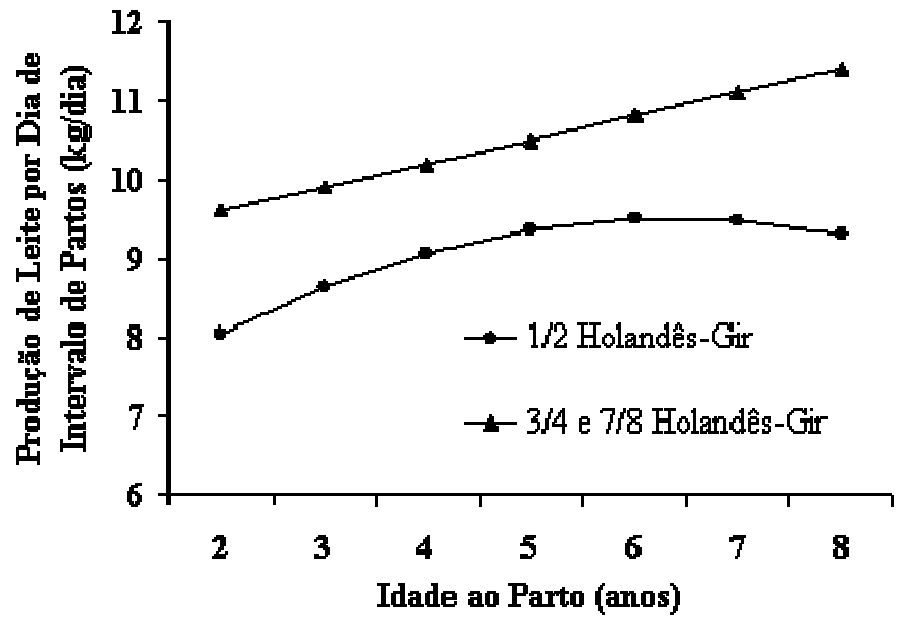

Figura 3. Regressão da produção de leite por dia de intervalo de partos (kg/dia), em relação a idade da vaca ao parto.

Os valores encontrados para as estimativas de repetibilidade da produção de leite foram considerados elevados, e indicam que, no sistema analisado, uma vaca teve grande possibilidade de repetir a produção observada em uma lactação nas lactações subseqüentes (Tab. 9), o que possibilita a seleção dos animais já a partir da primeira lactação. Estes resultados estão possivelmente relacionados à seleção dos animais, prática que permite a permanência na propriedade apenas daqueles animais com maiores produções. Os resultados obtidos por vários e registrados na literatura são menores que os estimados neste trabalho (Nobre et al. 1984; Polastre, 1985).

Tabela 9. Estimativas de repetibilidade da produção de leite de fêmeas mestiças Holandês-Gir, para vários conjuntos da lactação

\begin{tabular}{lcccc}
\hline \multirow{2}{*}{ Composição genética } & \multicolumn{4}{c}{ Lactação } \\
\cline { 2 - 5 } 1/2 Holandês-Gir & Todas & $1^{\mathrm{a}}$ e $2^{\mathrm{a}}$ & $2^{\mathrm{a}}$ e $3^{\mathrm{a}}$ & $1^{\mathrm{a}}$ e $3^{\mathrm{a}}$ \\
3/4 Holandês-Gir & 0,72 & 0,66 & 0,69 & 0,61 \\
7/8 Holandês-Gir & 0,69 & 0,54 & 0,69 & 0,54 \\
\hline
\end{tabular}

\section{CONCLUSÕES}

Nas condições do experimento os resultados refletem que os animais 3/4 Holandês-Gir representam a melhor opção para produção de leite. Maiores produções podem ser obtidas se as parições desses animais forem programadas para a época do final das chuvas. A utilização de sêmen de touros provados em avaliações genéticas utilizando populações de raça pura nos países de clima temperado não se justifica para produção de animais cruzados em países de clima tropical. 


\section{REFERÊNCIAS BIBLIOGRÁFICAS}

BARbosA, P. F.; SILVA, A. G; SILVA, A. C. D. P. et al. Produção de leite por dia de intervalo de partos em um rebanho mestiços EuropeuZebu em São Carlos, SP. In: REUNIÃO ANUAL DA SOCIDADE BRASILEIRA DE ZOOTECNIA, 38., 2001, Piracicaba. Anais... Piracicaba: ESALQ, 2001. CD ROM .

BASU, S. R.; TOMAR, S. S. Effect of the sire on the subsequent performance in the dam. Anim. Prod., v.32, p.155-158, 1981.

DAIRY BULLS. Disponível em: <http://www.dairy bulls.com> Acessado em: 15 jul. 2004.

DERESZ, F.; MATOS, L.L.; MOZER, O.L. et al. Produção de leite de vacas mestiças Holandês $x$ Zebu em pastagem de capim-elefante, com e sem suplementação de concentrado durante a época de chuvas. Arq. Bras. Med. Vet. Zootec., v.55, p.334-340, 2003.

DURÃES, M.C.; VALENTE, J.; FREITAS, A.F. et al. Diferenças entre produções de leite e gordura de vacas PC e PO da raça Holandesa no Estado de Minas Gerais. Arq. Bras. Med. Vet. Zootec., v.53, p.701-707, 2001.

FREITAS, A. F.; MILAGRES, J. C.; TEIXEIRA, N. M. et al. Produção de leite em rebanho leiteiro mestiço. Rev. Soc. Bras. Zootec., v.20, p.80-89, 1991.

FREITAS, M. S.; DURÃES, M. C.; FREITAS, A. F. et al. Comparação da produção de leite e de gordura e da duração da lactação entre cinco "graus de sangue" originados de cruzamentos entre Holandês e Gir em Minas Gerais. Arq. Bras. Med. Vet. Zootec., v.53, p.708-713, 2001.

GONÇALVES, T. M.; GABRIEL, A. M.; ALBUQUERQUE, F. T. et al. Produção de leite por dia de intervalo de partos em um rebanho mestiço Holandês-Gir em Itaguaí-RJ. In: REUNIÃO ANUAL DA SOCIEDADE BRASILEIRA DE ZOOTECNIA, 34., 1997, Juiz de Fora. Anais ... Juiz de Fora:UFRJ, 1997. Disponível em: $<\mathrm{http}: / /$ www.sbz.org.br/eventos $>$. Acessado em: 02 out. 2003.

HOURI NETO, M.; SILVA, H. M.; BERGMANN, J. A. G. Tendência genética para produção de leite em vacas Holandesas no Brasil e nos Estados Unidos da América. Arq. Bras. Med. Vet. Zootec., v.48, p.755-762, 1996.

JUNQUEIRA FILHO, G. N. Efeito de fatores fisiológicos e de meio sobre algumas caracteristicas reprodutivas e produtivas em vacas mestiças leiteiras. 1989. 103f. Dissertação (Mestrado em Zootecnia) - Escola de Veterinária, Universidade Federal de Minas Gerais, Belo Horizonte.

LEMOS, A. M.; TEODORO, R. L.; GONÇALVES, T. M. Intervalo de partos, produção de leite por intervalo de partos e número de serviços por concepção em vacas mestiças Holandês:Zebu. In: REUNIÃO ANUAL DA SOCIDADE BRASILEIRA DE ZOOTECNIA, 31., 1994, Maringá. Anais... Maringá: UFPR, 1994. p.209.

MATOS, N. J. M. Efeito de alguns fatores de meio sobre a produção total e produções parciais acumuladas de leite e periodo de lactação em rebanhos da raça Holandesa. 1983. 62f. Dissertação (Mestrado em Zootecnia) Escola de Veterinária, Universidade Federal de Minas Gerais, Belo Horizonte.

NOBRE, P. R. C.; MILAGRES, J. C.; CASTRO, A. C. G. et al. Fatores genéticos e de meio na produção de leite do rebanho leiteiro da Universidade Federal de Viçosa, Estado de Minas Gerais. Rev. Soc. Bras. Zootec., v.13, p.334-345 1984 .

PEREIRA, J. C.C. Interação genótipo-ambiente. In: . Melhoramento genético aplicado a produção animal. Belo Horizonte: FEP-MVZ, 1998. cap. 12, p. 130-133.

POLASTRE, R. Fatores genéticos e de ambiente do desempenho de vacas mestiças HolandêsZebu. 1985. 128f. Tese (Doutorado) Universidade Federal de Viçosa, Viçosa, MG.

REIS, S. R.; CARNEIRO, G. G.; TORRES, J. R. et al. Alguns fatores de ambiente que afetam a duração do período de lactação de um rebanho mestiço. Arq. Bras. Med. Vet. Zootec., v.35, p.715-722, 1983a.

REIS, S. R.; CARNEIRO, G. G.; TORRES, J. R. et al. Alguns fatores de ambiente que afetam a produção de leite de um rebanho mestiço. Arq. Bras. Med. Vet. Zootec., v.35, p.897-905, 1983b. 
USDA. Disponível em: Recife. Anais... Recife: UFRPE, 2002. CD ROM $<$ http://aipl.arsusda.gov/cgi-

bin/general/Qpublic/do.Q.cgi?qname=bullname \&single > Acessado em: 15 jul. 2004.

USER'S guide: basic and statistics. Cary, NC: SAS ${ }^{\circledR}$ Institute, 1996.

VALENTE, J.; FREITAS, A. F.; FREITAS, M. $\mathrm{S}$. et al. Estudo de algumas características da vida produtiva da vacas mestiças Holandês-Gir. In: REUNIÃO ANUAL DA SOCIDADE BRASILEIRA DE ZOOTECNIA, 39., 2002,

VASCONCELOS, J. L. M.; SILVA, H. M.; PEREIRA, C. S. et al. Aspectos fenotípicos da produção de leite e do período de lactação em vacas leiteiras com diferentes frações de sangue Holandês. Arq. Bras. Med. Vet. Zootec., v.41, p.465-475, 1989. 